\title{
Adhesion of Scaffolds with Implants to the Mandibular Bone with a Defect A finite element analysis
}

\author{
ALIN GABOR ${ }^{1 \#}$, CRISTIAN ZAHARIA ${ }^{1}$, VLAD TODERICIU², CAMELIA SZUHANEK*, ANDREEA CODRUTA COJ OCARIU1, \\ VIRGIL FLORIN DUMA3,4\#, CARMEN STICLARU4, MEDA LAVINIA NEGRUTIU1, IULIAN VASILE ANTONIAC ${ }^{5}$, COSMIN SINESCU1\# \\ ${ }^{1}$ Victor Babes University of Medicine and Pharmacy, Faculty of Dental Medicine, 2 Eftimie Murgu Sq., 300041 Timisoara, Romania \\ ${ }^{2}$ Radiology Center Dentavis, 20B Popa Sapca Str., 300057, Timisoara, Romania \\ ${ }^{3}$ Aurel Vlaicu University of Arad, 30M Optomechatronics Group, Faculty of Engineering, 77 Revolutiei Av., 310130 Arad, Romania \\ ${ }^{4}$ Polytechnic University of Timisoara, Faculty of Mechanical Engineering, 1 Mihai Viteazu Blvd., 300006, Timisoara, Romania \\ ${ }^{5}$ Polytechnic University of Bucharest, Faculty of Mechanical Engineering, 313 Splaiul Independentei, 060042, Bucharest, Romania
}

In most patients with complete or partially stretched edentations requiring a dental implant, there is insufficient alveolar bone for a proper morpho- functional prosthetic restoration. Therefore, in many cases a bone addition is required for the implant treatment. The aim of this study is to evaluate ex-vivo, with numerical simulations, a large mandibular bone defect that is restored by using a three-dimensional (3D) printed ceramic scaffold. In order to obtain a proper morphological and functional prosthetic restoration, a thick mandibular bone is utilized for the implant treatment. The polymeric scaffold is attached to the mandibular bone with one, two, or three implants. By scanning the mandible with MicroScribe $3 G$ and then employing a Finite Element Analysis (FEA) with Pro/Engineer and ANSYS 15, the study performs a numerical simulation and thus assesses the effects of the force applied to the scaffold.

Keywords: prosthetic restoration, mandibular bone, implant treatments, three-dimensional (3D) printing, polymeric scaffold, numerical simulations, Finite Element Analysis (FEA)

Most patients with complete or partially stretched edentations, who require a dental implant in order to achieve a proper morphological and functional prosthetic restoration, have insufficient alveolar bone. Therefore, a bone addition is required in many cases in order to complete the implant treatment [1].

Bone graft materials are usually divided into autologous, allogeneic, xenogenous, and synthetic. The autologous bone is considered to be the gold standard of the bone graft, because of its safety and efficiency [2]. On the other hand, the auto-tooth bone graft material can be considered as the most promising in guided bone surgery for bone regeneration, in order to achieve a prosthetic restoration [3-5].

Despite the high potential of bone regeneration, such a process may be accompanied by intraosseous defects caused by several aetiological factors, including surgical trauma, diseases, developmental deformities, or tumour resection. One of the goals of bone tissue therapies is to speed up the healing process by reducing the bone maturation period. However, additional donor surgery is required in order to achieve this, and the risk of complications occurs, including infection or pain. The amount of bone collection also has a certain limit. In addition, when allogeneic or xenogenic bone are utilized, contamination concerns can appear, while the effect of the osteogenesis is inferior to that of the autogenous bone $[6,7]$. There may be occult infections such as hepatitis or tuberculosis in the body of allogeneic bone, while the bovine bone that is often used as a source of xenogenic bone can carry the mad cow disease or other zoonoses. Synthetic bone on the other hand has no risk of contamination with such diseases, because it is a manufactured product, but it is only capable of osteoconduction [8,9].
Numerous strategies have been developed and tested to improve and accelerate bone regeneration, including the use of bone grafts and growth factors [10]. However, classical bone grafting techniques, when used, rarely provide satisfactory results, and the use of growth factors may be impossible due to the high costs involved. Alternatives that have been tested successfully in guided bone repair (GBR) are available, [10] and the use of demineralized human dentin matrix (DHDM) is one of the options to solve this problem [5,11-15]. This DHDM consists of $55 \%$ inorganic hydroxyapatite (HA) and $45 \%$ organic substances. Inorganic HA possesses bone properties in the combination and dissociation of calcium and phosphate. Organic substances include bone morphogenetic proteins that have a capacity for osteoinduction, as well as type I collagen identical to the one found in the alveolar bone. The bone additive material of human dentin is useful because it maintains an excellent bone regeneration capacity and minimizes the possibilities of foreign body reaction, genetic diseases, or disease transmission. The material properties of the mandibular bone have been extensively studied, [16-22] but fewer studies have been focused on the assessment of the entire assembly of the mandibular bone with the scaffold.

3 D printed scaffolds dedicated for a special bone defect, opened to the surface of the mandible bone, allow for obtaining an optimal vertical and horizontal bone level, as well as volume [23]. In order to have a good stability of the mandible-scaffold complex, usual implants could be used to fix this structure. Also, the scaffold must have an optimum porosity in order to obtain an adhesion to the bone [7].

Different materials could be used for these 3D printed scaffolds, including porous ceramics, foams, and alumina

\footnotetext{
*email: cameliaszuhanek@umftro; Phone: 0040724251240
} 
[23]. Also, different technologies could be employed to obtain scaffolds, besides 3D printing, including fused deposition modelling, lamination, and laser sintering [23]. How ever, 3D printing has several advantages compared to other additive methods: it is a direct deposition method; it allows the fabrication of heterogeneous tissue construction scaffolds; it is a powder manufacturing method, therefore it can achieve 3D models with computer aided design (CAD) by using the patient's CAD data [23-25]. 3D printing also combine high surface area and good porosity with a satisfactory mechanical strength [26]. For example, 3Dprinted bioresorbable and personalized scaffolds were demonstrated to treat periodontal defects, with a $3 \mathrm{~mm}$ gain of clinical attachment and partial root coverage [27].

The present paper brings forward such a solution, based on a 3D personalized printed scaffold for a mandible bone defect [28]. This scaffold is going to be fixed to the mandible body by usual implants. Considering the magnitude of the defect, one, two, or three implants may have to be used for this fixture.

Taking into account the above, the aim of this study is to evaluate, by using numerical simulations, the adhesion of a ceramic scaffold graft to a mandibular bone that has a large bone defect which prevents the clinician to use dental implants as a treatment plan. The second aspect to be studied is the number of implants that is necessary in order to assure a proper resistance of the construct to the usual level of the forces that act upon the mandible. Some of these techniques were previously used in orthodontic treatment[31,32].
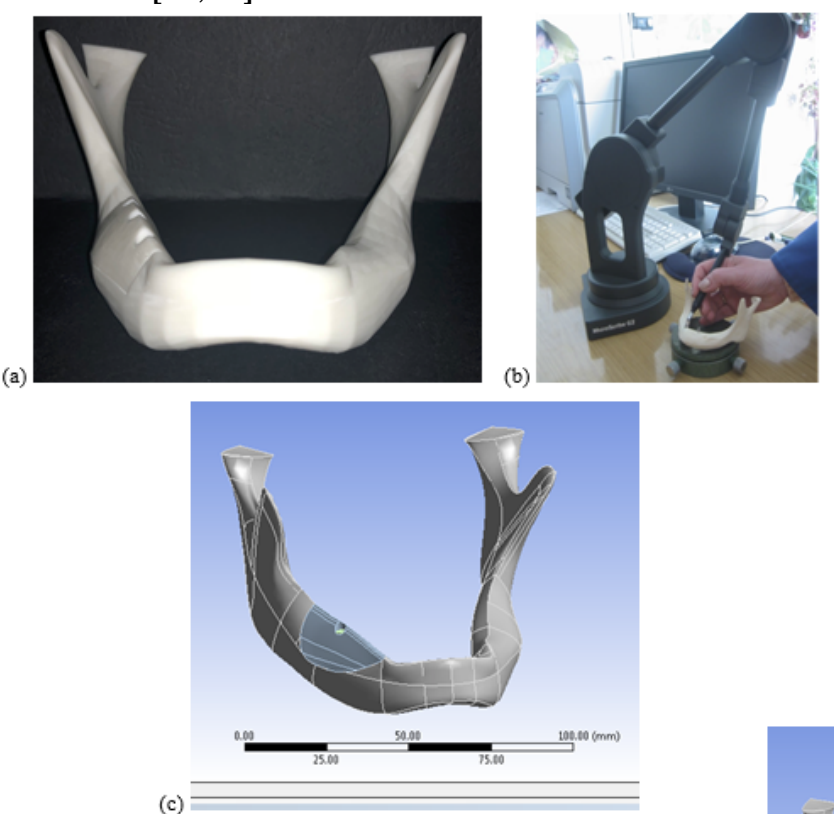

Fig. 1. (a) The photo of the mandible considered in this study; (b) the scanning of the mandible, using MicroScribe

G2; (c) the 3D model of the mandible (with a single implant), obtained after the scanning.

Fig. 2. (a) The 3D mandible models considered in this study; (b) the discretization of the models - for (1) one, (2) two, and (3) three implants.

\section{Experimental part}

Material and methods

We used ex-vivo in this study a mandibular bone with a significant bone defect that prevents a proper implant surgery - fig. 1(a).

Figure 1(b) shows the scanning of the mandible, performed with MicroScribe G2 (Immersion Corporation, San J ose, CA, USA), with an accuracy of $0.38 \mathrm{~mm}$ and in a spherical workspace of $75.4 \mathrm{~mm}$. A cloud of points was measured, and itwas then processed in ProEngineer-Creo2 (PTC Inc., USA) - fig. 1(c). The work has been done starting from points, lines, and then passing to solid surfaces. The mandibles dimensions, as defined by its bounding box are: $98.692 \mathrm{~mm} \times 73.94 \mathrm{~mm} \times 81.769 \mathrm{~mm}$.

Figure 2(a) presents the three situations that are analyzed. In the first one only an implant was inserted in the middle of the scaffold, in order to stabilize this scaffold. In the second situation two implants were used, inserted at $10 \mathrm{~mm}$ from each other, and at $21.5 \mathrm{~mm}$ from the margins of the scaffold. In the third situation three implants were inserted at $10 \mathrm{~mm}$ from each other, and at $16.5 \mathrm{~mm}$ from the margins of the scaffold. The implants used are made of titanium; they have a diameter of $3.5 \mathrm{~mm}$ and a length of $11 \mathrm{~mm}$. Each scaffold has a length of $60 \mathrm{~mm}$.

Using ANSYS 15 (ANSYS Inc., Canonsburg, PA, USA), it was then possible to obtain a numerical simulation of the effect of the different forces applied on the scaffold - using a Finite Element Analysis (FEA). [29,30] 3847 elements were considered, as well as 8032 nods. A surface mesh of triangular elements was utilized; it has a minimal dimension of an element of $0.29 \mathrm{~mm}$. Figure 2(b) shows this meshing of the mandible bone that has introduced inside its defect the polymeric scaffold with one, two, or three dental implants.

\section{Results and discussions}

Figure 3(a) shows the load that was applied on the mandible bone which has on the bone defect the polymeric scaffold implemented with one, two, or three implants; the loading force in all three cases was $F=300 \mathrm{~N}$.

Figure 3(b) presents the stress that appears in the 3D model bone with the bone defect for each of the three cases above (i.e., with one, two, or three dental implants). Figure 3(c) shows the stress that appears in the entire 3D model of the mandible, after the scaffold was fixed.

Figure 4(a) shows the stress that appears in the 3D model of the polymeric scaffold. In parallel, fig. 4(b) shows the

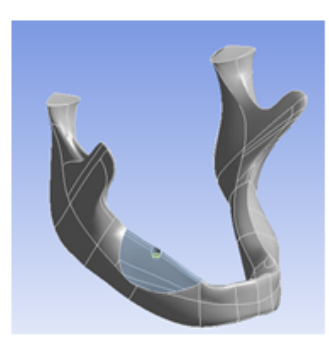

(a1)

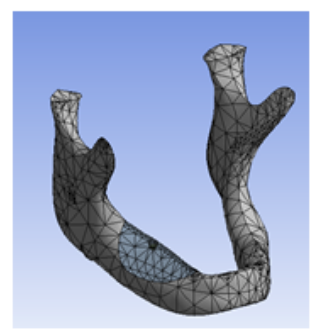

(b1)

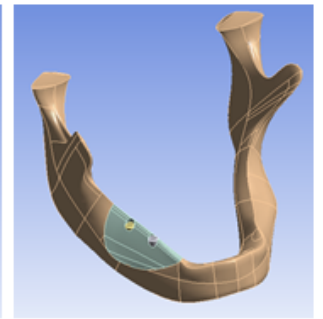

(a2)

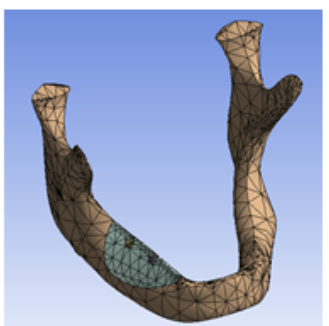

(b2)

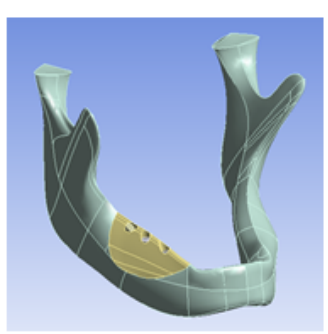

(a3)

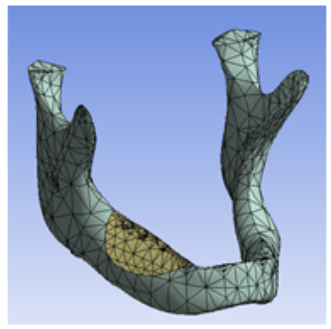

(b3) 
(a1)

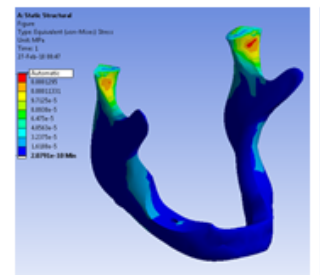

(b1)

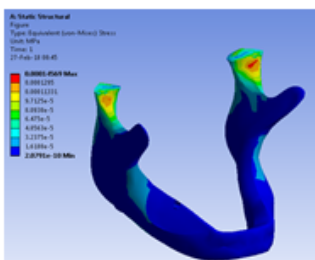

(c1)

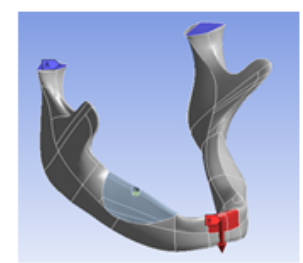

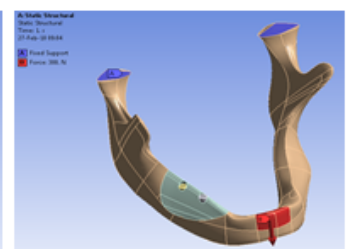

(a2)

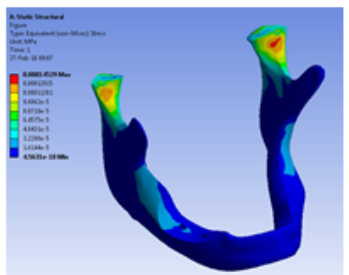

(b2)

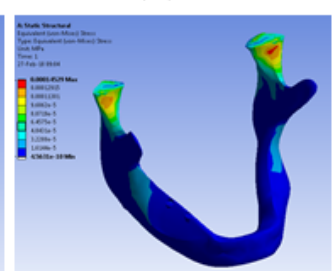

(c2)

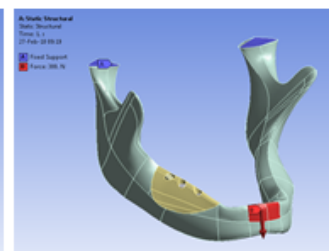

(a3)

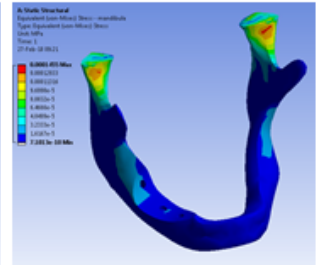

(b3)

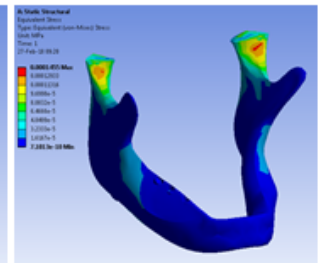

(c3)

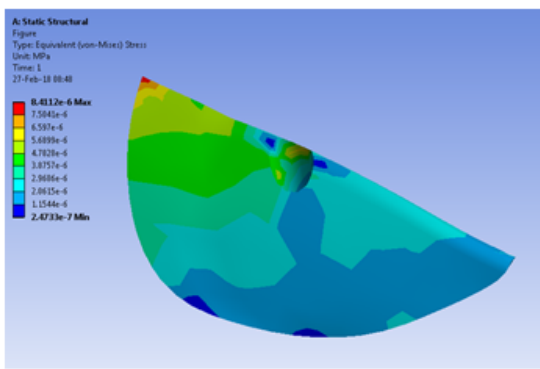

(a1)

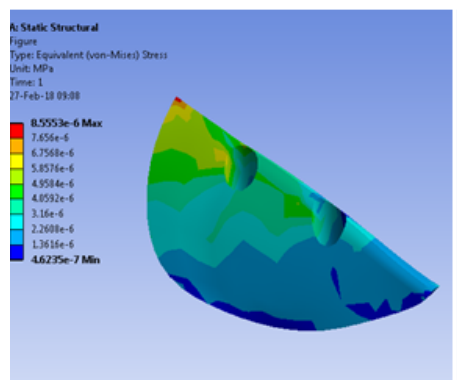

(a2)

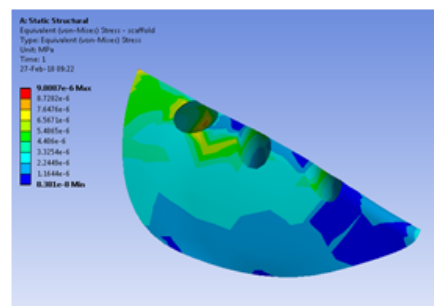

(a3)

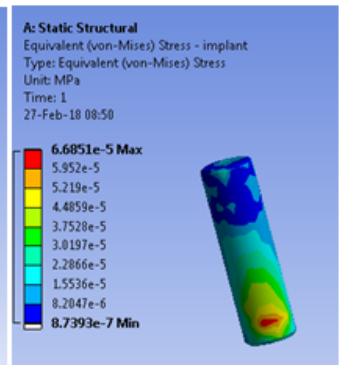

(b1)

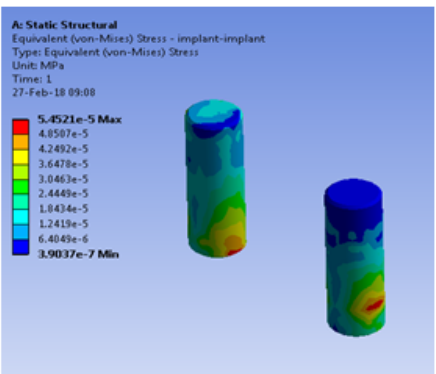

(b2)

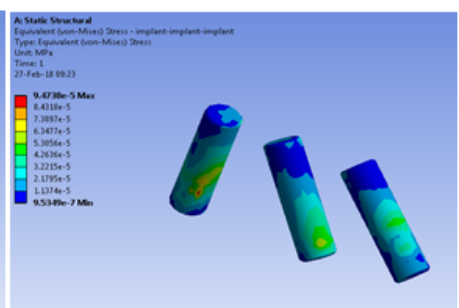

(b3)
Fig. 4. (a) The stress that appears in the 3D model of the polymeric scaffold; (b) the stress that appears in the 3D model of the dental implants- each of these aspects considered for (1) one, (2) two, and (3) three implants

stress that appears in the 3D model of the dental implants utilized in each case.

Figure 5(a) shows the mandible-scaffold contact area, in the three cases, of one, tw 0 , or three dental implants. In parallel, figure $5(b)$ shows the contact pressure between the mandible and the polymeric scaffold, for the same cases.
Fig. 3. (a) The loads that where applied on the mandible bone; (b) the stress that appears in the entire $3 \mathrm{D}$ model bone with the bone defect; (c) the stress that appears in the 3D model bone with the scaffold implanted - each of these aspects considered for (1) one, (2) two, and (3) three implants

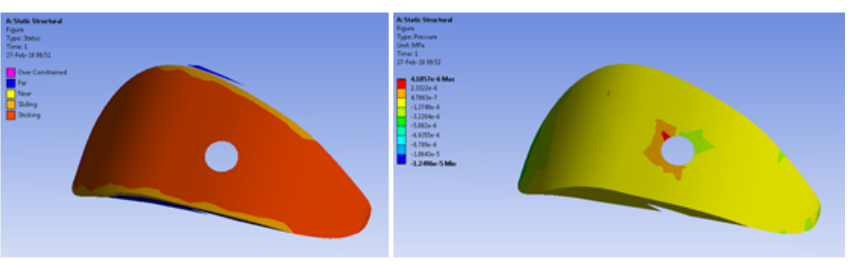

(a1)

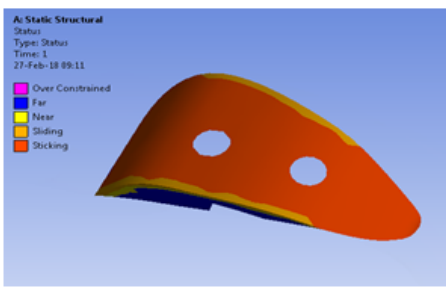

(a2)

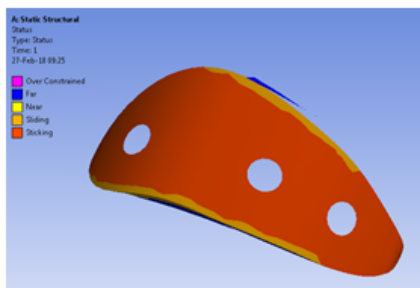

(a3)

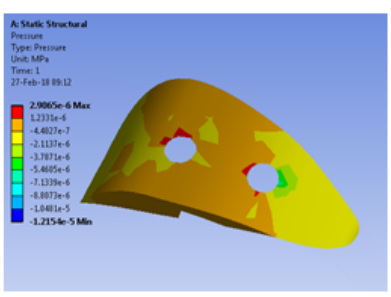

(b2)

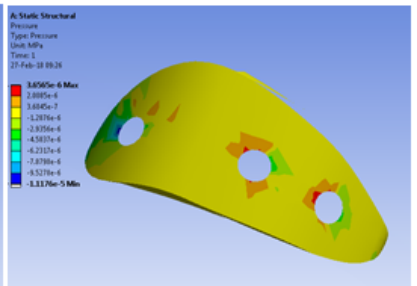

(b3)

Fig. 5. (a) The mandible-scaffold contact area; (b) the contact pressure between the mandible and the polymeric scaffold - each of these aspects considered for (1) one, (2) two, and (3) three implants

Finally, figure 6 shows the sliding tendency of the polymeric scaffold on the mandible bone defect, for each of the three characteristic cases considered.

For this study, several aspects have been studied for a certain force applied on the scaffold, i.e. its effects on the implant, on the scaffold, and on the bone defect. By applying a force in the menton region of the mandible, the stress was well-distributed, and the main area affected was the condyles one. In contrast, on the implant and scaffold regions the stress was minimal. The same result was remarked for the 3D model bone with the defect, for 


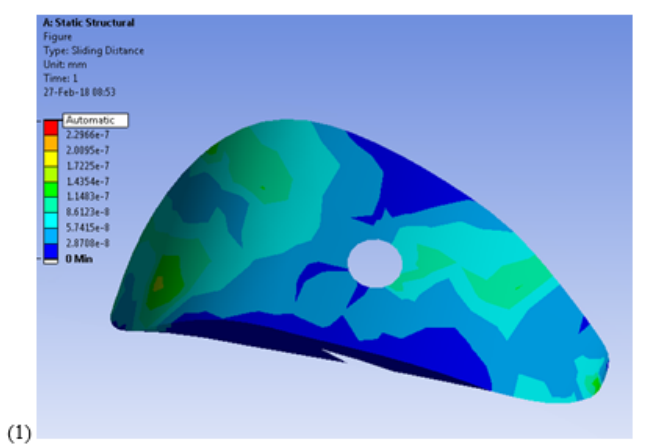

(1)
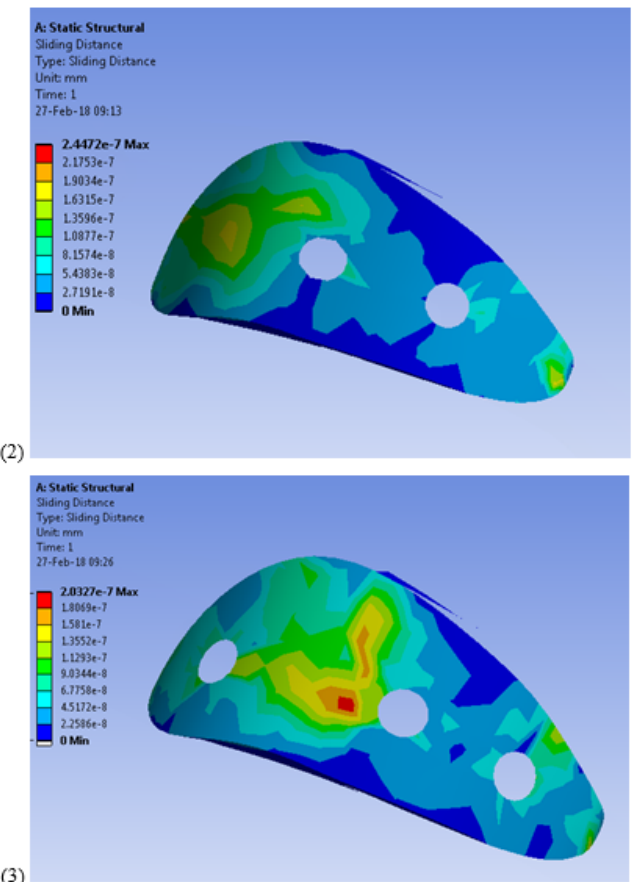

Fig. 6. The sliding tendency of the polymeric scaffold on the mandible bone defect - for (1) one, (2) two, and (3) three implants.

all the three considered cases: with one, two, or three implants (fig. 2).

When analyzing the stress that appears in the 3D model of the polymeric scaffold (fig. 3), it can be remarked that the smallest value of the stress was on the first probe. The highest value of the stress was obtained for the third probe: $16.61 \%$ higher than for the first one. In the second one the stress was higher than the first one with $1.71 \%$. However, looking at the results obtained on the stress produced in the implants, there was a higher amount of stress in the case of three implants, with $73.75 \%$ more that in the case of two implants, where the smallest value of the stress was calculated. The case of one implant has a stress higher with $22.62 \%$ than the one of two implants.

The pressure on the scaffold was higher for the case of one implant; the best case was the one with two implants
- fig. 5(b). Using the simulations, the measured pressure was with $25.81 \%$ higher for three implants, compared with the two implants case, while the one implant case had a pressure higher with $44.01 \%$ than the two implants case. The amount of stress accumulated in the area which surrounds the implants was minimal.

By measuring the contact area when the polymeric scaffolds are implemented with one, two, or three dental implants, it can be remarked that there are no significant differences between the three considered cases -fig. 5(a). However, the contact pressure between the mandible and the polymeric scaffold implemented with one, two, or three implants was different: contrary to expectations, a higher pressure in the second case was remarked, as compared with the first one, with one implant. The best case from this point of view was the one with three implants.

By analyzing the sliding tendency of the polymeric scaffold on the mandible bone defect, the three implants scaffold developed a higher stress as compared with the one implant scaffold (fig. 6). The best case from this point of view was the one with two implants.

A summary of all these remarks, made from different points of view, is made in table 1- in order to provide users with an overview of advantages and drawbacks of the three considered cases.

Besides the aspects pointed out above, there is a most important factor which has not been yet taken into account in this in vitro study, i.e. the patient. In a clinical situation, the one that decides how many implants are used is the patient and she/he has to be informed about all the advantages and drawbacks of the three cases described previous.

In this study one has concluded that the best modality of treatment was the one with two implants. The pressure and the forces were thus well-distributed along the implants, the bone defect, and the polymeric scaffold. The one implant scaffold case showed a good stability of the scaffold, a good distribution of the stress along the polymeric scaffold, but it had a smaller percentage of success, compared with the two implants case.

Taking all these factors into account, one may conclude that the case with just one implant is the most accessible and can be used with good results in practice. One of its most important disadvantages is that the amount of pressure was shown in this study to be higher than for the other cases, with two or three implants scaffolds. How ever, the pressure was better distributed on a larger surface of the scaffold.

Comparing the cases of two and three implants, the difference between them is not too significant, as from Table 1 both of them have certain stronger and weaker points. However, taking also into account the costs

Table 1

THE BIOMECHANICAL CHARACTERISTICS OF THE SCAFFOLD IMPLANTS COMPLEX IN THE CONSIDERED SITUATIONS

\begin{tabular}{|c|c|c|c|c|c|c|c|}
\hline Nr. & Sample type & $\begin{array}{c}\text { Scaffold } \\
\text { with } 1 \\
\text { implant }\end{array}$ & $\begin{array}{l}\text { Scaffold } \\
\text { with } 2 \\
\text { implants }\end{array}$ & $\begin{array}{c}\text { Scaffold } \\
\text { with } 3 \\
\text { implants }\end{array}$ & $\begin{array}{c}1 \\
\text { implant }\end{array}$ & $\begin{array}{c}2 \\
\text { implants }\end{array}$ & $\begin{array}{c}3 \\
\text { implants }\end{array}$ \\
\hline 1. & $\begin{array}{l}\text { Equivalent } \\
\text { (von-Mises) } \\
\text { stress [MPa] }\end{array}$ & $\begin{array}{l}\text { (a1)-Fig. } 4 \text {. } \\
8.4112 \mathrm{e}-6 \\
\operatorname{Max}\end{array}$ & $\begin{array}{c}\text { (a2)-Fig. } 4 \\
8.5553 \mathrm{e}-6 \\
\operatorname{Max}\end{array}$ & $\begin{array}{c}\text { (a3)-Fig. } 4 . \\
9.8087 \mathrm{e}-6 \\
\text { Max }\end{array}$ & $\begin{array}{l}\text { (b1) } \\
\text { Fig.4. } \\
6.6851 \mathrm{e}-5 \\
\text { Max }\end{array}$ & $\begin{array}{c}\text { (b2)- } \\
\text { Fig.4. } \\
5.4521 \mathrm{e}-5 \\
\text { Max }\end{array}$ & $\begin{array}{c}(b 3)- \\
\text { Fig.4. } \\
9.4738 \mathrm{e}-5 \\
\text { Max }\end{array}$ \\
\hline 2. & $\begin{array}{l}\text { Pressure } \\
\text { [MPa] }\end{array}$ & $\begin{array}{c}\text { (b1) - Fig. } 5 \text {. } \\
4.1857 \mathrm{e}-6 \\
\text { Max }\end{array}$ & $\begin{array}{c}\text { (b2)-Fig. } 5 . \\
2.9065 \mathrm{e}-6 \\
\text { Max }\end{array}$ & $\begin{array}{c}\text { (b3)-Fig. } 5 . \\
3.6565 \mathrm{e}-6 \\
\text { Max }\end{array}$ & $y_{1}$ & - & - \\
\hline 3. & $\begin{array}{c}\text { Sliding } \\
\text { distance }[\mathrm{mm}]\end{array}$ & $\begin{array}{c}\text { (1)-Fig.6. } \\
2.2966 \mathrm{e}-7 \\
\text { Max }\end{array}$ & $\begin{array}{c}\text { (2)-Fig.6. } \\
2.4472 \mathrm{e}-7 \\
\mathrm{Max}\end{array}$ & $\begin{array}{c}\text { (3) - Fig. } 6 \\
2.0327 \mathrm{e}-7 \\
\text { Max }\end{array}$ & - & - & - \\
\hline
\end{tabular}


involved, the two implants solution seems to be enough and the most appropriate treatment decision.

\section{Conclusions}

The implants improve the resistance of the bone; with more implants the resistance is better, but the cost of the treatment is also increasing. Therefore, it was shown in this study that a number of two implants is the best option of treatment, giving a good stability of the scaffold. Also, the treatment cost is easier accepted by the patient.

Acknowledgements: This work was supported by the Romanian National Authority for Scientific Research; CNDI-UEFISCDI GrantPN-III-P2-2.1-PTE2016-0181 ( http://3om-group-optomechatronics.ro/). Cosmin Sinescu also acknowledges the support of the Victor Babes University of Medicine and Pharmacy of Timisoara (GrantPIII-C2-PCFI (2015-2016), DENTALOCT).

\section{References}

1. N. TOSCANO, N. SHUMAKER, D. HOLZCLAW, The art of block grafting - A review of the surgical protocol for reconstruction of alveolar ridge deficiency. The Journal of Implant and Advanced Clinical Dentistry 2010, 2(2), 45-66.

2. P. V. GIANNOUDIS, H. DINOPOULOS, E. TSIRIDIS, Bone substitutes: An update. Injury. Int J Care Injured 2005, 36S, S20-S27.

3. S.-M. PARK, I.-W. UM, Y.-K. KIM, K.-W. KIM, Clinical application of auto-tooth bone graft material. J Korean Assoc Oral Maxillofac Surg 2012, 38, 2-8.

4. M. MURATA, T. AKAZAWA, M. MITSUGI, I.-W. UM, K.-W. KIM, Y.-K. KIM (2011). Human Dentin as Novel Biomaterial for Bone Regeneration, Biomaterials - Physics and Chemistry, Prof. Rosario Pignatello (Ed.), ISBN: 978-953-307-418-4, InTech, Available from: http:// www.intechopen.com/books/biomaterials-physics-and-chemistry/ human-dentin-as-novel-biomaterial-for- bone-regeneration.

5.K-W. KIM, Bone Induction by Demineralized Dentin Matrix. Maxillofac Plast Reconstr Surg 2014, 36(2), 50-56.

6. V. KARAGEORGIOU, D. KAPLAN, Porosity of 3D biomaterial scaffolds and osteogenesis. Biomaterials 2005, 26, 5474-5491.

7. X. ZHANG, L. XIN, Z. YANG, Z. TONG, X. SUN, L. ZHANG, M. ZHANG, W. ZHENG, Allogeneic Osteoblasts Combined with beta-Tricalcium Phosphate to Repair of Bone Defect. Journal of Biomaterials and Tissue Engineering 2016, 6(4), 270-276.

8. A. ASHMAN, Postextraction ridge preservation using synthetic alloplast. Implant Dent 2000, 9, 168.

9. D. PUPPI, F. CHIELLINI, A. M. PIRAS, E. CHIELLINI, Polymeric materials for bone and cartilage repair. Progress in Polymer Science 2010, 35(4), 403-440.

10. Y. M. KOLAMBKAR, K. M. DUPONT, J. D. BOERCKEL, N. HUEBSCH, D. J. MOONEY, D. W. HUTMACHER, R. E. GULDBERG, An alginatebased hybrid system for growth factor delivery in the functional repair of large bone defects. Biomaterials 2011, 32(1), 65-74.

11. I.-W. UM, S.-H. JUN, P.-Y. YUN, Y.-K. KIM, Histological Comparison of Autogenous and Allogenic Demineralized Dentin Matrix Loaded with Recombinant Human Bone Morphogenetic Protein-2 for Alveolar Bone Repair: A Preliminary Report. Journal of Hard Tissue Biology 2017, 26(4), 417-423.

12. R. TANOUE, K. OHTA, Y. MIYAZONO, J. IWANAGA, A. KOBA, T. NATORI, O. IWAMOTO, K.-I. NAKAMURA, J. KUSUKAWA, Threedimensional ultrastructural analysis of the interface between an implanted demineralised dentin matrix and the surrounding newly formed bone. Scientific Reports 2018, 8, 2858.

13. MD. A. KABIR, M. MURATA, T. AKAZAWA, K. KUSANO, K. YAMADA, M. ITO, Evaluation of perforated demineralized dentin scaffold on bone regeneration in critical-size sheep iliac defects. Clinical Oral Implants Research 2017; 28(11): E227-E235.
14. S.-Y. KIM, Y.-K. KIM, Y.-H. PARK, J.-C. PARK, J.-K. KU, I.-W. UM, J.Y. KIM Evaluation of the Healing Potential of Demineralized Dentin Matrix Fixed with Recombinant Human Bone Morphogenetic Protein2 in Bone Grafts. Materials 2017, 10(9), 1049.

15. S-M PARK, D. H. KIM, E.-K. PANG, Bone formation of demineralized human dentin block graft with different demineralization time: In vitro and in vivo study. Journal of Cranio-maxillofacial Surgery 2017, 45(6), 903-912.

16. G. ODIN, C. SAVOLDELLI, P.-O. BOUCHARD, Y. TILLIER, Determination of Young's modulus of mandibular bone using inverse analysis. Medical Engineering \& Physics 2010, 32(6), 630-637.

17. E. LAKATOS, L. MAGYAR, I. BOJ TAR, Material Properties of the Mandibular Trabecular Bone. J Med Eng. 2014, 470539.

18. J. LEMAITRE, Handbook of Materials Behavior Models. New York, NY, USA: Elsevier; 2001.

19. F. LINDE, Elastic and viscoelastic properties of trabecular bone by a compression testing approach. Danish Medical Bulletin 1994, 41(2), 119-138.

20. A. ODGAARD, F. LINDE, The underestimation of Young's modulus in compressive testing of cancellous bone specimens. Journal of Biomechanics 1991, 24(8), 691-698.

21. M. J. CIARELLI, S. A. GOLDSTEIN, D. DICKIE, et al., Experimental determination of the orthogonal mechanical properties, density, and distribution of human trabecular bone from the major metaphyseal regions utilizing materials testing and computed tomography. Transactions of the Orthopedic Research Society 1986, 42.

22. G. ODIN, C. SAVOLDELLI, P.-O. BOUCHARD, Y. TILLIER, Determination of Young's modulus of mandibular bone using inverse analysis. Medical Engineering \& Physics 2010, 32(6), 630-637.

23. S. H. JARIWALA, G. S. LEWIS, Z. J. BUSHMAN, J. H. ADAIR, H. J. DONAHUE, 3D Printing of Personalized Artificial Bone Scaffolds. 3d Printing and Additive Manufacturing. 2015, 2(2), 56-64. doi:10.1089/ 3dp. 2015.0001

24. S.-I. ROOHANI-ESFAHANI etal. Design and Fabrication of 3D printed Scaffolds with a Mechanical Strength Comparable to Cortical Bone to Repair Large Bone Defects. Sci. Rep. 2016, 6, 19468; doi: 10.1038/ srep19468

25. G. TURNBULL, J. CLARKE, F. PICARD, L. JILA, F. HAN, B. LI, W. SHU. 3D Bioactive composite scaffolds for bone tissue engineering. Bioactive Materials 2018, 3(3), 278-314.

26. YONGXIANG LUO, DONG ZHAI, ZIGAUNG HUAN, HAIBO ZU, CHENGTIE WU. 3D printing of hollow struts-packed bioceramic scaffolds for bone regeneration. ACS Applied Materials \& Interfaces, 7(43) October 2015

27. G. RASPERINI, S. P. PILLIPCHUK, C. L FLANGEN, W. V. GIANNOBILE, 3D-printed Bioresorbable Scaffold for Periodontal Repair. Journal of Dental Research, 2015, 94(9Suppl).

28. GABOR, A., HOSSZU, T., ZAHARIA,C., KOZMA,A., COJOCARIU, A. C., NEGRUTIU, M.L., SZUHANEK, C. SINESCU,C., 3D Printing of a Mandibular Bone Deffect. Mat.Plast., 54,no.1, 2017, p.29

29. A. J. DAVIES, The Finite Element Method. An introduction with partial differential equations. Oxford University Press, $2^{\text {nd }}$ Edition, NY, 2011.

30. G. R. LIU, S. S. QUEK, The Finite Element Method: A Practical Course. Butterworth-Heinemann (Elsevier), $2^{\text {nd }}$ Edition, Amsterdam, 2014.

31. POPA, A., SZUHANEK, C., BRAD, S., Accurate Determination for Orthodontic Mini-implant Placement Using Acrylic Resin Surgical Guide and CBCT. Mat. Plast., 53, no. 2, 2016, p.287

32. SZUHANEK, C, FAUR N., CERNESCU A., Biomechanical 3D analysis of stress induced by orthodontic implants. Key Engineering Materials, vol.399(2009), pp 194-204.

$\overline{\text { Manuscript received: } 09.05 .2018}$ 